\title{
Launching of Series Fabrication of the LHC Main Quadrupoles
}

\author{
R. Burgmer, R. Bussjäger, D. Krischel, M. Peyrot, J.-M. Rifflet, P. Schmidt, F. Simon, and T. Tortschanoff
}

\begin{abstract}
A collaboration agreement between CERN and CEASaclay resulted in the successful development and construction of prototypes of the LHC main superconducting quadrupole magnets and their assembly into cold masses. A call for tender was issued in October 1999 and led to the adjudication of a contract to ACCEL Instruments. A number of components will be provided by CERN to be used either directly by ACCEL for integration into the cold mass units or by subsuppliers before delivery to ACCEL. During the series fabrication, CEA's engineers and technicians, already experienced from their prototype work, will ensure the technology transfer and the technical follow-up in the factory. ACCEL had to adapt two large fabrication halls to the needs of the magnet fabrication and the cold mass assembly. Procedures for a tight quality assurance and the logistics for the timely supply of components and a high production rate are being established in close collaboration by the three parties concerned.
\end{abstract}

Index Terms - Large Hadron Collider, LHC, quadrupoles, series fabrication, superconducting magnets.

\section{INTRODUCTION}

$\mathbf{T}$ HE LARGE Hadron Collider (LHC) at CERN will be equipped with 360 main quadrupoles in the arc of the machine and with 32 in the so-called dispersion suppressor regions. These superconducting magnets are of the two in one type, which means that two quadrupole apertures are combined in the same yoke, same cold mass and same cryostat.

The design of the magnets, their prototype fabrication, the integration of the quadrupole magnets with the other corrector magnets into their cold masses [1], [2], [7] and the design of their cryostats [3] have been described earlier. In [4]-[6] the performance of the prototypes are presented both for the training behavior and measured field quality in terms of multipole components.

The development of these magnets is the result of a close collaboration between CERN and the CEA-Saclay laboratory in France. This collaboration concerns the design, prototyping and technology transfer to industry as well as the following up of the series fabrication by CEA. After the successful campaign of the prototype phase, CERN has launched the series fabrication of the cold masses of the quadrupole magnets. Based on a detailed Technical Specification edited in close collaboration between CERN and CEA, a competitive Call for Tender was sent out in October 1999. Eight companies submitted offers, which were thoroughly evaluated. Finally, the fabrication

Manuscript received September 24, 2001.

R. Burgmer, R. Bussjäger, D. Krischel, and P. Schmidt are with ACCEL Instruments GmbH, Bergisch-Gladbach, Germany.

M. Peyrot, J.-M. Rifflet, and F. Simon are with CEA Saclay, France.

T. Tortschanoff is with CERN, Geneva, Switzerland.

Publisher Item Identifier S 1051-8223(02)03477-2. of the magnets and their assembly into cold masses were entrusted to the German company ACCEL Instruments $\mathrm{GmbH}$ in Bergisch-Gladbach near Cologne. The contract was signed in July 2000 .

\section{MAIN PARAMETERS}

Table I recalls the main parameters of these magnets, for more details, see [4]. The twin-aperture quadrupole magnets are housed in a cold mass together with the arc corrector magnets. On one end the dipole-sextupole correctors are mounted. On the other end, the connection end, either the octupole, respectively, the tuning or skew quadrupole correctors. The vessel of the cold mass functions as the stiffening element of the assembly and at the same time as helium pressure vessel.

\section{RESPONSIBILITIES FOR THE SERIES FABRICATION}

As CEA-Saclay has been executing the design and prototyping, the laboratory remains responsible for all technical aspects and the fabrication drawings. These drawings follow an approval circuit at CERN before they are labeled "for execution" and submitted to the manufacturer.

ACCEL Instruments $\mathrm{GmbH}$, as the manufacturer, is responsible for the correct execution of all components and their final assembly. This will be verified during the magnetic measurements at room temperature. Not being at the base for the design and not providing themselves critical items like the superconducting cables, ACCEL is not liable for the nominal performance of the magnets, unless faulty manufacturing can be proven. CERN is responsible for all contractual and commercial issues and for the definition of all mechanical and electrical interfaces to the cryostats and the machine. CERN's obligation includes also the fault-free and timely delivery of numerous components as defined in the Technical Specifications.

\section{COMPONENTS PROVIDED By CERN}

A number of components are provided by CERN to the manufacturer. This is either because they are the same as for the dipole magnets and thus economies of scale can be achieved or they are subject of other specialized orders or collaboration.

In the first category we have the following:

- the superconducting cables, being the same as that used for the outer layer of the main dipole magnets;

- the polyimide material for the cable and ground insulation;

- the low carbon steel for the yoke laminations;

- the cold bore and heat exchanger tubes;

- the instrumentation and its wires;

- the interconnection bellows. 
TABLE I

MAIN PARAMETERS AND CHARACTERISTICS OF THE LHC QUADRUPOLE MAGNET AND COLD MASS

\begin{tabular}{lrl} 
& \multicolumn{2}{c}{ Value } \\
\hline Injection field gradient (0.45 TeV beam energy) & 14.5 & $\mathrm{~T} / \mathrm{m}$ \\
Nominal field gradient (7 TeV beam energy) & 223 & $\mathrm{~T} / \mathrm{m}$ \\
Nominal current & 11,870 & $\mathrm{~A}$ \\
Operating temperature & 1.9 & $\mathrm{~K}$ \\
Magnetic length at $1.9 \mathrm{~K}$ & 3.1 & $\mathrm{~m}$ \\
Cold mass length at 293 K, between end covers & 5355 & $\mathrm{~mm}$ \\
Cold mass weight & 6.5 & $\mathrm{~T}$ \\
Stored energy (both apertures) at 7 TeV & 0.79 & $\mathrm{MJ}$ \\
Ultimate operational field gradient & 241 & $\mathrm{~T} / \mathrm{m}$ \\
Peak induction in coil at ultimate gradient & 7.4 & $\mathrm{~T}$ \\
Gradient at short sample field limit & 278 & $\mathrm{~T} / \mathrm{m}$ \\
Distance between aperture axes at 1.9 K & 194.00 & $\mathrm{~mm}$ \\
Inner coil diameter at 293 K & 56.00 & $\mathrm{~mm}$ \\
Outer coil diameter at 293 K & 118.60 & $\mathrm{~mm}$ \\
\hline
\end{tabular}

The second category contains:

- the austenitic steel for the collars;

- the various corrector magnets;

- the current feed bus-bars;

- the quench protection heaters;

- the quench protection diodes.

The timely delivery of all these components requires a major logistics effort by CERN. The delivery time requirements depend also on whether the components are to be treated before assembly into the cold mass, like the cable insulation or the steel to be fine-blanked, or whether the pieces can go directly into the cold mass, like the corrector magnets. Any delays or faulty deliveries may entail assembly stoppages at ACCEL and eventually cause penalty payments to CERN.

\section{COMPONENTS to BE SubCONTRACTED By ACCEL}

For a number of services and components ACCEL had to place contracts to subsuppliers all over Europe. The most significant subsupplies concern the following items:

- application of cable insulation;

- interlayer and interturn insulation;

- ground insulation;

- fine-blanking of collars and yoke laminations;

- keying systems;

- machining of filler pieces and other glass-fiber epoxy components;

- inertia tubes and cold mass end covers.

\section{TEChNOLOGY TRANSFER}

The agreement with CEA-Saclay includes, as aforementioned, the transfer of technology to the manufacturer. Already before and during the tendering time the candidate firms were invited to attend meetings at Saclay for familiarizing them with the techniques and fabrication methods developed during the prototype phase. Representatives of all bidding firms could see the dedicated tooling and witness some phases of the fabrication.

For the series fabrication at ACCEL Instruments, CEA is sending, on a semipermanent mission, two technicians for performing this technology transfer and later the technical follow-up of the fabrication. These senior technicians have all the detailed experience of the prototype phase gained in about 10 years and in earlier similar projects.

ACCEL, a management buyout of the former SIEMENS-KWU magnet and accelerator department, has a lot of experience in designing and manufacturing, e.g., the HERA and SSC quadrupole magnets. This experience is used to assure manufacturing of the LHC magnets according to industrial standards.

Part of the technology transfer was the partial transfer of the prototype tooling to the manufacturer. This not only helps ACCEL in achieving some experience by using the tooling at an early stage of the contract, but it also results in duplication of the tooling, which is needed for reaching the peak production rate of four magnets and cold mass assemblies per week.

\section{QUALITY CONTROL}

The quality control is an important issue for the series fabrication of this kind of magnets. The tight tolerances are needed not only for the magnet alignment and for achieving the requested performance, but also to assure the correct field quality. The difficult cryogenic environment, making it extremely hard to correct any manufacturing error or late detected fault, asks for almost continuous control during fabrication. ACCEL has edited for each operation, both fabrication and control measurements, written procedure documents. ACCEL is establishing a fully computerized quality control and traveler system based on the requirements specified in CERN's quality assurance documents as well as specific requirements. Any detected nonconformity will be documented and communicated to both CERN and CEA.

The use of a powerful relational database as well as the identification of all components via a bar-code system is foreseen from the beginning.

The different stages of the quality assurance start by the regular geometrical and electrical verification of components, both those coming from subsuppliers or those made in-house. For the final geometrical verifications, especially of those concerning the mechanical interfaces, CERN provides two Laser Trackers of latest technology to ACCEL.

The field quality of each assembled collared coil unit will be measured at room temperature conditions before it is mounted, in pairs, into its yoke. CERN and CEA have developed dedicated measuring benches of which one will be at ACCEL's premises and operated by their own technicians. Further warm magnetic measurements will be performed once a cold mass is finished and closed. From the experience gained from the prototype quadrupoles and other superconducting magnets one knows that the correlation between warm and cold measurements is largely sufficient. These measurements may also comprise a verification of the magnetic axes.

With all these provisions one aims to detect as early as possible any badly made coils or magnets. Procedural flow-charts have been set up of how to handle any fault or nonconformity and to establish the chain of decisions and responsibilities.

During the present preparatory phase and during the beginning of the fabrication some changes may appear either 
necessary for the project or advantageous for the manufacturer without hampering the performance. This type of changes are formally treated as Technical Change Requests if they are proposed by the manufacturer or as Technical Change Orders if they are issued by CERN or CEA. Any of these changes are applied only after their implications have thoroughly been studied and full agreement has been reached. In this case all three parties sign a written document.

\section{Present State of Preparation for the Series FABRICATION}

Already before the adjudication of the contract ACCEL has found in the industrial zone of Troisdorf, situated between Cologne and Bonn, two adjacent factory halls of 2500 and $1850 \mathrm{~m}^{2}$. Although these halls had been in a bad state and serving since many years only as storage, they appeared suitable for the task of fabricating the 400 quadrupole units (including 8 spares). Once the quadrupole contract was signed, the halls could be rented and their renovating work could be launched. This activity consisted in equipping both halls with a new solid and painted concrete floor and new thermal insulation. Further all walls, ceilings, windows and the full structure had to be cleaned and painted thoroughly. In one hall, a 5-m deep pit was dug in order to give sufficient space under the crane for the vertical assembly of the cold masses, Fig. 1.

All cranes had to be refurbished and a new one was installed. All the electrical and sanitary equipment was renewed. Social rooms for the personnel and offices had to be installed as well as fully new computer network equipment and access control system. By spring 2001, most of this work has been completed and the installation of tooling could start. For the time being this presently installed tooling consist of CEA's prototype tooling, most of it operational, Fig. 2. ACCEL has received their own newly designed collaring press and one of the four heating units powering the polymerization presses. In addition, auxiliary tools and equipment needed for manufacturing has been procured and installed by ACCEL.

ACCEL has placed orders for most of the components with their sub-suppliers and deliveries should start in September and October 2001.

ACCEL was given some spare components available from the prototype work at CEA-Saclay and has already wound and polymerized one complete coil. ACCEL has been trying out the new collaring press (Fig. 3) and wishes to proof that by adopting their own design they can simplify the collaring procedure by using a one piece keying system for locking the collared coils instead of the three piece keying used by CEA for the prototypes. The three piece keying includes sliding strips for the insertion of the keys, which ACCEL wishes to suppress. Before an agreement can be reached on this, ACCEL has to demonstrate in a mock-up test the validity of this solution which presents a major change with respect to the prototype magnets.

\section{CONCLUSION}

The series production has been launched and is presently still in its preparation phase. The selected company, ACCEL Instruments, has proceeded in a highly professional way for installing

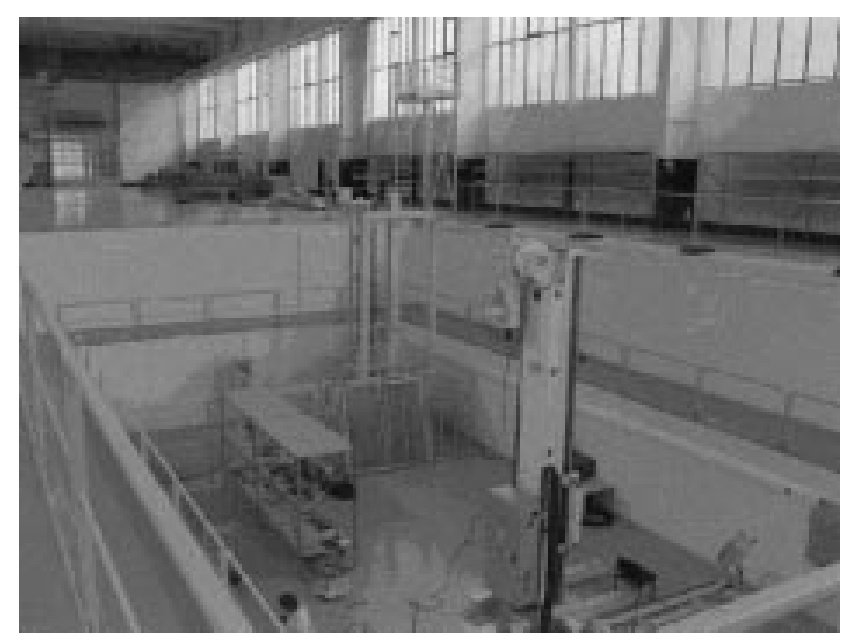

Fig. 1. Pit in fabrication hall with tooling for the vertical assembly of yokes and cold masses under preparation.

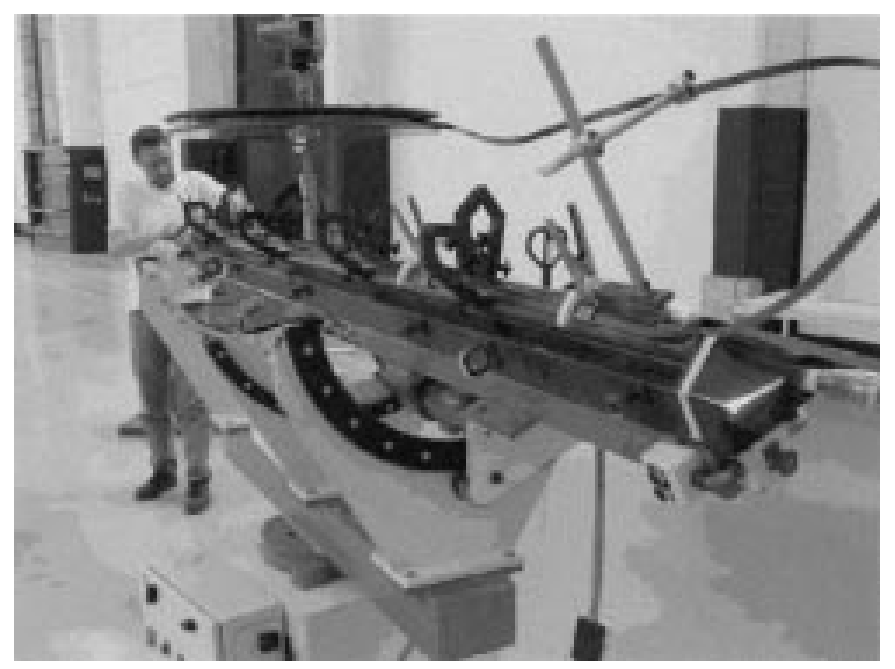

Fig. 2. Coil winding machine in operation.

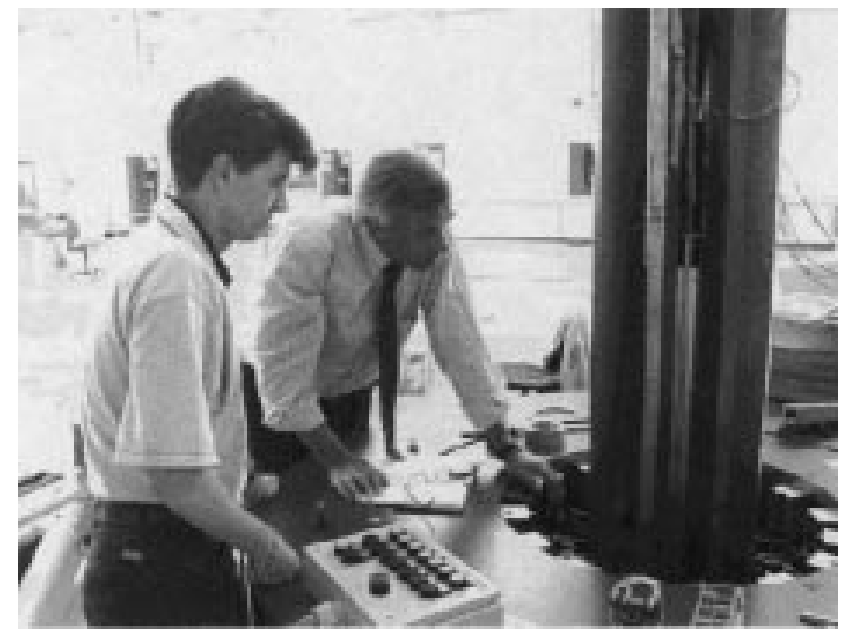

Fig. 3. New collaring press operating for first mock-up test in fabrication hall. A hole in the ground provides the vertical passage of the collared coils.

a brand new fabrication facility. ACCEL has already started setting up its procedures by making a number of test and operational trials. They can rely to a high extent on the experience 
gained by CEA-Saclay from where originated the quadrupole design and where the prototypes were made and ACCEL's own experience from former successful projects. CEA continues to provide the technology transfer and will also be responsible for the technical follow-up.

\section{ACKNOWLEDGMENT}

The authors wish to acknowledge with gratitude the contributions and support of their numerous colleagues at CERN, CEA and ACCEL Instruments.

\section{REFERENCES}

[1] T. Tortschanoff et al., "The short straight sections for the LHC," in Proc. PAC97 Conf., Vancouver, Canada, 1997.
[2] M. Peyrot, J.-M. Rifflet, F. Simon, T. Tortschanoff, and P. Vedrine, "Construction of the new prototype of main quadrupole cold masses for the arc short straight sections of LHC," in Proc. MT-16, Ponte Vedra Beach, FL, 1999.

[3] L. Nielsen, V. Parma, T. Renaglia, P. Rohmig, T. Tortschanoff, J.-B. Bergot, Ph. Dambre, E. Roy, D. Vincent, M. Peyrot, J.-M. Rifflet, and F. Simon, "A modular design for the 56 variants of the short straight section in the arcs of the Large Hadron Collider (LHC)," in Proc. EPAC-2000, Vienna, 2000.

[4] T. Tortschanoff, J. Billan, L. Bottura, V. Remondino, A. Siemko, M. Peyrot, J. M. Rifflet, and F. Simon, "Performance of series-design prototype main quadrupoles for the LHC," in Proc. EPAC-2000, Vienna, 2000 .

[5] J. Billan, V. Remondino, A. Siemko, T. Tortschanoff, M. Peyrot, J.-M. Rifflet, and F. Simon, "Performance of prototypes and start up of series fabrication of the LHC arc quadrupoles," in Proc. PAC2000 Conf., Chicago, IL, USA, 1997.

[6] J. Deregel, A. Devred, C. Gourdin, B. Hervieu, T. Ogitsu, M. Peyrot, J. M. Rifflet, T. Schild, F. Simon, T. Tortschanoff, and K. Tsuchyia, "Test results of the third LHC main quadrupole magnet prototype at CEASaclay," Proc. MT-17, submitted for publication.

[7] M. Peyrot, J.-M. Rifflet, F. Simon, T. Tortschanoff, and P. Vedrine, "Construction of the new prototype of main quadrupole cold masses for the arc short straight sections of LHC," IEEE Trans. Appl. Superconduct., vol. 10, p. 170, Mar. 2000. 